\title{
SECOND LANGUAGE ACQUSITION: GRAMMAR CONSTRUCTION OR PIECEMEAL LEARNING?
}

\author{
Cecile le Roux
}

\section{Introduction}

This paper deals with the question of whether the learning of a second or further language is a phenomenon of the same kind as the learning of a first language. The question arises because of the frequently observed failure of learners to achieve native-like proficiency in a second language. Whereas first language learning is almost always successful, the outcome of second language learning quite often falls far short of complete mastery and is typically non-uniform across learners. The failure of second language leamers to achieve native-like proficiency is often referred to as "fossilization" in the literature on second language acquisition. The term "variability" is used to refer to the non-uniformity of the outcome of second language acquisition across learners.

A few remarks on terminology must be made at this point. Firstly, I shall use the term "first language", or " $\mathrm{Ll}$ " for short, to refer to the language which children acquire first, i.e. their native or mother tongue. The term "second language", or "L2" for short, will be used to refer to any language which is acquired by someone who already knows a first language. Thus, the term "second language/L2" will be used irrespective of whether the language acquired is a second, third, fourth or fifth language. Secondly, no distinction will be made between "a second language/L2", as defined here, and "a foreign language". That is, the term "second language/L2 acquisition" will be used, irrespective of whether or not the language to be acquired is used in the community. ${ }^{1}$ Thirdly, the terms "acquisition" and "learning" will be used interchangeably. Both "acquisition" and "learning" must be taken to refer to what happens unconsciously (typically in a naturalistic setting), as well as to what happens consciously (typically in a classroom setting). ${ }^{2}$

One approach towards explaining fossilization in L2 acquisition is to assume that the cognitive subsystem responsible for $\mathrm{Ll}$ acquisition is not involved in $\mathrm{L} 2$ acquisition, or is 
involved in a different way (see, e.g., Cook and Newson 1996:294ff). On this approach it is assumed that $\mathrm{Ll}$ acquisition is mediated by a cognitive subsystem which is uniquely dedicated to the acquisition of language. This language-specific cognitive system is assumed to take the form of a Universal Grammar (UG). It consists of principles common to all natural languages. Because human beings are innately equipped with knowledge of UG, it is claimed, children have the capacity to acquire the language which they are exposed to from birth without having to be taught. All that is needed to activate this capacity, i.e. to "trigger" UG, and to set $\mathrm{Ll}$ acquisition in motion is exposure to a language. Once UG has been triggered, $\mathrm{Ll}$ acquisition proceeds rapidly, effortlessly and uniformly across learners. Moreover, all $\mathrm{Ll}$ Jearners of a given language end up having the same internalized knowledge, or grammar, of the L1, despite quite significant differences in the amount and quality of the input that they receive. ${ }^{3}$

The outcome of $\mathrm{L} 2$ acquisition is less successful and less uniform than that of $\mathrm{L} 1$ acquisition, it is argued, because UG does not play the same role in $\mathrm{L} 2$ acquisition as it does in $\mathrm{L1}$ acquisition. There is a range of views amongst $L 2$ theorists about what exactly a "lesser" role for UG in L2 acquisition entails. The most extreme position is that of Bley-Vroman (1990) who hypothesizes that once an $L 1$ has been acquired, UG no longer exists as an acquisition device. In the course of Ll acquisition UG is supplanted by, or changes into, the Ll grammar. Hence, once an $L 1$ grammar has emerged, UG is no longer available to play an active role in further language acquisition. Acquisition of an L2, on this hypothesis, is mediated by the same general cognitive problem-solving mechanisms that are involved in the acquisition of non-linguistic types of knowledge and skills. This hypothesis is known as the Fundamental Difference Hypothesis. ${ }^{4}$

A less extreme position, let's call it the UG Hypothesis, is that L2 learners do have access to UG, but that UG does not operate in exactly the same way as it does in $L 1$ acquisition. For example, Schwartz and Sprouse $(1994,1996)$ and White (1989) believe that UG drives L2 acquisition as it does $\mathrm{Ll}$ acquisition, but that the outcome is different because the parameters associated with the principles of UG have already been set to their $\mathrm{Ll}$ values. ${ }^{5}$ Input interacts differently with a UG for which the parameter values have already been set than with a UG with open parameter values. As a result, the grammar that emerges from the interaction, 
usually referred to as "the interlanguage grammar", may be different from the grammars of native speakers of the L2. Similarly, Vainikka and Young-Scholten (1994, 1996) hypothesize that UG plays exactly the same role in L2 acquisition as in L1 acquisition, the only difference being that the initial L2 grammar includes some L1 parameter values (e.g. the value of the parameter determining the position of heads in phrases - see note 5 above). ${ }^{6}$

A slightly different version of the UG Hypothesis holds that, although L2 leamers do not have access to UG directly, they do have access to those aspects of UG that are manifested in the L1. On this hypothesis, invariant principles of UG that are instantiated in the L1, and the L1 manifestations of principles that permit parametrical variation (in other words the $\mathrm{Ll}$ values of parameters), can constrain the grammars constructed by L2 learners. Crucially, however, UG is no longer seen as the mechanism actively driving acquisition (see, e.g., Clahsen and Muysken 1989 and Schachter 1990).

\section{Grammar construction vs piecemeal learning}

How is it possible to distinguish between acquisition that does and acquisition that does not involve UG? For an answer to this question one needs to consider the way in which L2 acquisition is construed on the Fundamental Difference Hypothesis on the one hand and the UG Hypothesis on the other hand.

We shall consider two versions of the UG Hypothesis. On the first version, L2 acquisition is claimed to be driven by essentially the same mechanism as $\mathrm{L} 1$ acquisition, viz. the triggering of parameter values. Instead of rules being learnt (e.g. through hypothesis formation), values or settings for pre-existing parameters are assumed to be automatically activated, or "triggered", by the linguistic input to which the learner is exposed. ${ }^{7}$ Given that the learner encounters an adequate range of utterances in the target language, the appropriate values are automatically assigned to the parameters. Thus, knowledge of the L2 unfolds or grows, to use some of the terms that are employed to describe $\mathrm{L} 1$ acquisition. ${ }^{8}$ Not all aspects of the L1 are claimed to be acquired in this way, of course: only the core grammatical features that are language-specific instantiations of universal principles and parameters. Specifically, the lexical items, i.e. the morphemes, words and other fixed expressions of the language, have to 
be learnt along with their meanings and quite detailed information concerning the kinds of sentence structures they will fit into.

The parameter-triggering view of L2 acquisition has certain implications. The setting, or fixing, of a parameter value is crucially claimed to have multiple effects. These multiple effects are usually referred to as "a clustering of properties" in the literature (see, e.g., Schwartz 1996 and White 1992). What this means is that a language which has the value $X$ for a given parameter is expected to have the cluster of properties $a, b$ and $c$, whereas $a$ language with a different value, say $\mathrm{Y}$, for the same parameter is expected to have a different cluster of properties, say $d$, e and $f$. In other words, a switch in parameter setting from value $X$ to value $Y$ is expected to bring about not just one, but several simultaneous changes in the properties of a language. Instead of having the properties $a, b$ and $c$, the language is expected to have the properties $d, e$, and $f$.

On the second version of the UG Hypothesis, L2 acquisition is claimed to be constrained by UG as instantiated in the LI grammar of the L2 learner. That is, the interlanguages constructed by L 2 learners are claimed to be constrained by the parameter settings of the L 1 . This version differs from the one described above in not providing for the resetting of parameters from their $\mathrm{L} 1$ to their $\mathrm{L} 2$ values. Instead of a "parameter-triggering" view, it is a "parameter-transfer" view. Rather than being actively involved in L2 acquisition, allowing new parameter values to be triggered by the $L 2$ input, UG is involved only insofar as it constrains the values that parameters can have in the interlanguage grammar to those of the L1. On this view, as on the parameter-triggering view, the language produced on the basis of the interlanguage grammar is expected to exhibit clusters of properties: in this case the clusters of properties related to the $L I$ parameter values.

On both versions of the UG Hypothesis, the interlanguage grammars constructed by $\mathrm{L} 2$ learners are claimed to incorporate parameter values. The fact that the properties related to a given parameter value cluster together in the way described above implies, of course, that a language cannot have any one of the properties in a cluster without having the others as well. That is, if the pararneter is set to the value $X$, the resulting language must necessarily have all three the properties related to $X$, i.e. the properties $a, b$ and $c$. It cannot have only one or two of the properties in a cluster, but not the rest. This implication provides us with a way of 
determining whether or not $U G$ is involved in $L 2$ acquisition. If $U G$ is involved, then parameter-triggering or parameter-transfer should occur. On the parameter-triggering view, it should be possible for parameters to be reset from their $\mathrm{Ll}$ value to the $\mathrm{L} 2$ value. ${ }^{9}$ The resetting of a parameter should affect all the properties related to that parameter. Suppose, for example, that the learner's $\mathrm{L} 1$ has the parameter value $\mathrm{X}$ and the $\mathrm{L} 2$ has the parameter value $Y$. Then, once parameter resetting has occurred, we expect the learner's interlanguage to have the properties $d, e$ and $f$ that are related to the parameter value $Y$ (the $L 2$ value), rather than the properties $a, b$ and $c$ that are related to the parameter value $X$ (the $L 1$ value). We do NOT expect the learner's interlanguage to have only one or two of the properties that are related to the $\mathrm{L} 2$ parameter value, or some of the properties related to the $\mathrm{Ll}$ parameter value and some of the properties related to the $L 2$ parameter value.

Similarly, on the parameter-transfer view, we expect the learner's interlanguage to have the properties $\mathrm{a}, \mathrm{b}$ and $\mathrm{c}$ that are related to the parameter value $\mathrm{X}$ (the $\mathrm{Ll}$ value). We do NOT expect the learner's interlanguage to have only one or two of the properties that are related to the LI parameter value.

If, by contrast, an L2 learner's interlanguage were found to display some but not all of the properties related to a given parameter value, then it would be possible to conclude that no parameter-resetting or parameter transfer has occurred. It would indicate that the leamer is acquiring parametrical properties in a piecemeal fashion, as though they were completely unselated. This, in turn, would imply that the learner is not engaged in UG-mediated grammar construction. Rather the learner would have to be assumed to be engaged in the piecemeal discovery of the properties of the language through non-language-specific cognitive processes such as hypothesis formation and testing.

This paper will consider the question of whether $L 2$ learners engage in UG-mediated grammar construction, or whether they merely learn parameter-related properties of the L2 in a piecemeal fashion as though they were completely unrelated. Data from two learners acquiring French as an L2 will be considered, one a native speaker of Afrikaans and the other a native speaker of English. The presentation of the data is preceded by a brief discussion of the relevant grammatical differences between Afrikaans and English on the one hand, and French on the other hand (section 3). Section 4 contains a statement of the predictions that the 
UG Hypothesis makes about the properties of utterances produced by L2 Jearners of French whose $\mathrm{L} 1$ is English and Afrikaans respectively. This is followed by a short description of the studies from which the data were taken (section 5). The analysis of the data is presented in section 6 . The findings of the analysis are discussed and the conclusions presented in section 7. The final section, section 8 , takes a brief look at some implications of the findings for $\mathrm{L} 2$ teaching.

\section{Structural differences between Afrikaans, English and French}

There are a number of word order differences between English on the one hand, and Afrikaans and French on the other hand, which are the result of parametrical differences between these languages.

First, in Afrikaans and French finite lexical verbs (i.e. finite main verbs as opposed to auxiliary verbs) appear to the left of the negative element in (main) clauses, as is clear from a comparison of (1)(a) and (l)(b) with (1)(d) and (l)(e). English, by contrast, does not allow. finite lexical verbs to appear to the left of the negative element in main clauses, as can be seen by comparing (1)(c) and (1)(f). (The finite lexical verb in each sentence is underlined and the negative element appears in upper case.)

(1) $\mathrm{V} \sim \mathrm{NEG}$
(a) Hy soen NIE sy vrou nie.
(b) Il n'embrasse PAS sa femme.
(c) *He kisses NOT his wife.

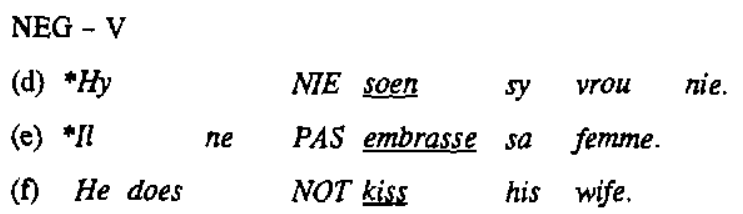

Before we continue, a note on the way in which sample sentences are presented may be in order. The sentences in (1)(a)-(c) are essentially direct translations of each other. So are the 
sentences in (1)(d)-(f). Note, however, that some lexical items are not translated. In the case of (1) this includes the second nie ('not') in Afrikaans and the clitic ne/ $n$ ' ('not') in French which is prefixed to the verb in sentences containing a negative element such as pas. Corresponding words in the Afrikaans, French and English sentences appear directly below each other typographically. A typographical gap in a sentence indicates that the corresponding sentence in one or both of the other two languages contains a lexical item for which there is no equivalent in the sentence in question. For example, the two gaps following $H y$ in sentence (I)(d) indicate that the Afrikaans sentence does not contain an equivalent for the English auxiliary does in sentence ( $(1)(\mathrm{f})$ or for the French clitic ne in sentence (I)(e).

A second difference between Afrikaans and French on the one hand and English on the other hand is illustrated in (2). In Afrikaans and French finite lexical verbs can appear to the left of the subject in interrogatives, as shown in (2)(a) and (2)(b). This is not permitted in English, as is clear from the ungrammaticality of (2)(c), the grammatical equivalent of which is Does he kiss his wife? (The finite lexical verb in each sentence is underlined and the subject appears in upper case.)

(2) V - SUBJ
(a) Soen
HY sy vrou?
(b) Embrasse-t-IL sa femme?
(c) * Kisses HE his wife?

A third word order difference between Afrikaans and French on the one hand and English on the other hand shows up in sentences containing sentence-medial adverbs. In Afrikaans and French finite lexical verbs must appear to the left of sentence-medial adverbs in main clauses, as is clear from a comparison of (3)(a) and (3)(b) with (3)(d) and (3)(e). In English, finite lexical verbs are not permitted to the left of sentence-medial adverbs, as shown by a comparison of (3)(c) and (3)(f). (The finite lexical verb in each sentence is underlined and the sentence-medial adverb appears in upper case.)

(3) V - ADV
(a) Hy soen
DIKWELS sy vrou.
(b) Il embrasse SOUVENT sa femme.
(c) ${ }^{*} \mathrm{He}$ kisses OFTEN his wife. 

$A D V-V$
(d) *Hy DIKWELS soen sy vrou.
(e) *Il SOUVENT embrasse sa femme.
(f) He OFTEN kisses his wife.

It is clear from the word order patterns illustrated in (1) to (3) above that finite lexical verbs in Afrikaans and French occur in a variety of clause positions, whereas English finite lexical verbs do not. The explanation of this difference to be assumed in this paper is the one provided within the 'Government and Binding' (GB) model of generative syntactic theory (see, e.g., Haegeman 1994 and Cook and Newson 1996). ${ }^{10}$ The explanation is outlined briefly below.

It is assumed that a verb (V) and its arguments, i.e. the noun phrases (NPs) with which it enters into thematic role relationships, are generated within the verb phrase (VP) at the level of deep structure (D-structure). ${ }^{11}$ The VP therefore represents the lexical-thematic structure of a sentence. Auxiliary verbs, by contrast, do not enter into thematic relationships. They are therefore assumed to be part of the functional rather than the lexical-thematic structure of a sentence. Hence they are generated outside the VP. ${ }^{12}$ Given these assumptions, the D. structure of the various Afrikaans, French and English sentences given in (1)-(3) above is as shown in (4). It is assumed for the sake of the discussion that Afrikaans is underlyingly SVO like French and English. ${ }^{13}$ (The abbreviation COMPL stands for "complement". The complement can be an NP (noun phrase), an AP (adjectival phrase), a PP (prepositional phrase) or a CP (complementizer phrase, i.e. a full sentence).) 
(4)

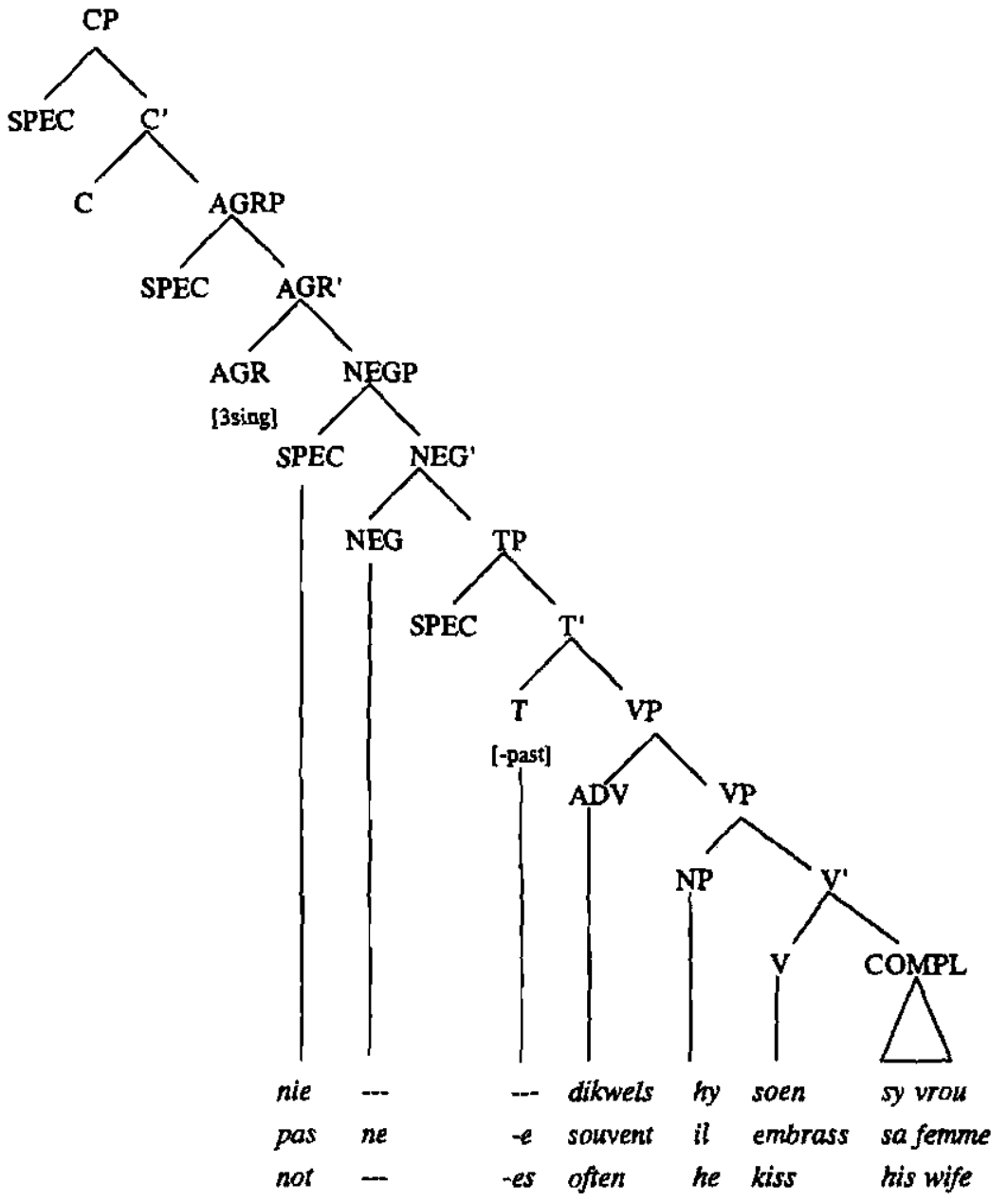

The surface structures (S-structures) of the Afrikaans and French sentences in (1) and (3) above are derived by

i. moving the verb via the intervening head positions $T$ (where the verb picks up the tense feature/morpheme) and NEG (where the clitic ne is prefixed to the French verb) to AGR (where the verb picks up the person and number agreement feature/morpheme), and

ii. moving the subject NP to the specifier position in AGRP (where it is assigned nominative case by AGR). 
These movements result in the S-structure (5). ${ }^{14}$

(5)

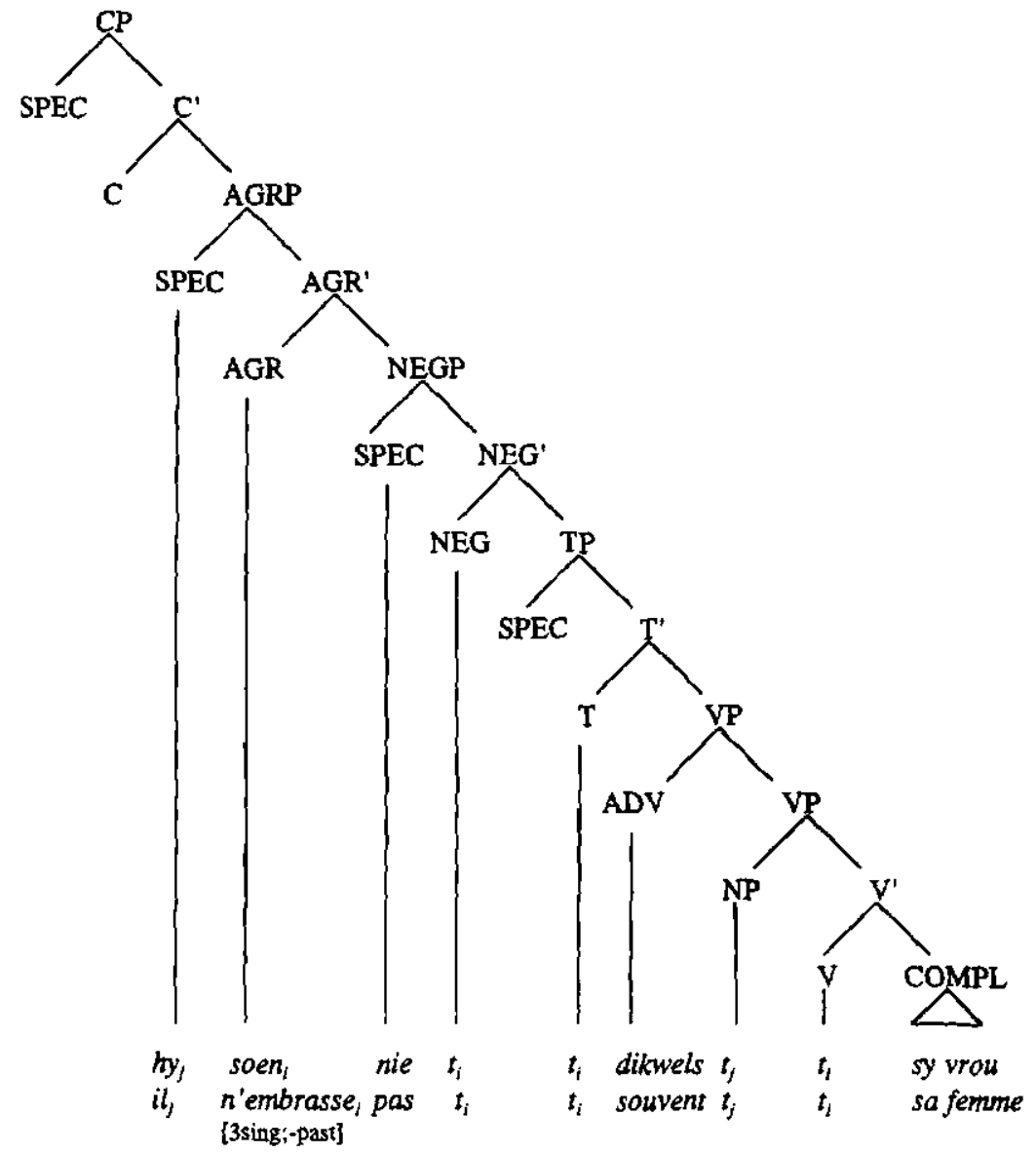

In (5), " $t$ " represents the traces of moved constituents and the subscripts identify the constituent of which $t$ is the trace, i.e. $t_{i}$ is the trace of the verbs soen $n_{1}$ and embrasse.

The S-structure (5) underlies all of the following sentences, depending on which of the optional constituents NEGP and ADV are present in the structure:
(6) (a) Hy soen nie sy vrou nie.
( $=(1)$ (a) above)
(b) Il n'embrasse pas sa femme.
$(=(1)(b)$ above) 
(7) (a) Hy soen dikwels sy vrou. (= (3)(a) above)

(b) Il embrasse souvent sa femme. $\quad(=(3)$ (b) above)

(8) (a) Hy soen nie dikwels sy urou nie. he kisses not often his wife not

(b) $I l$ n'embrasse pas souvent safemme. he kisses not often his wife

(9) (a) Hy soen sy vrou.

he kisses his wife

(b) Il embrasse sa femme.

he kisses his wife

The interrogative sentences in (2) above, repeated as (10) below, can be derived by a further application of verb movement to (5). This would result in the verb moving to $C$, i.e. to the left of the subject. The movement would occur whenever $\mathrm{CP}$ is marked as being interrogative, that is when $\mathrm{C}$ has the feature [ $+\mathrm{WH}]$.
(10) (a) Soen hy sy vrou?
$(=(2)(a)$ above $)$
(b) Embrasse-t-il sa femme?
$(=(2)(b)$ above)

Note that the movement of the subject and the verb shown in (5) is obligatory. Finite verbs (whether lexical verbs or auxiliaries) in Afrikaans and French must move to acquire the tense and agreement features associated with the functional categories AGR and T. The subject has to move to the specifier position in AGRP so that it can be assigned case by the verb in AGR. Since these movements are obligatory, sentences in which a finite verb does not move to AGR are predicted to be ill-formed. This prediction is correct, as is clear from the ill-formedness of the sentences in (1)(d)-(e) and (3)(d)-(e) above.

The S-structure of the English sentences in (1) and (3) is derived by

i. leaving the lexical verb in its D-structure position within VP,

ii. moving the subject NP to the specifier position in AGRP (where it is assigned nominative case by AGR), and

iii. moving an auxiliary (if there is one) via $T$ to AGR to pick up the tense and agreement features associated with these functional categories or, in the absence of an auxiliary, lowering the features associated with AGR and T onto the lexical verb in VP. ${ }^{15}$ 
Let us see how this analysis accounts for the English facts in (1)-(3) above. Sentence (1)(f) He does not kiss his wife is predicted to be well-formed. In $(1)(f)$ the lexical verb kiss semains in place in the VP. An auxiliary, does, moves to AGR to pick up the tense and agreement features. ${ }^{16}$ In sentence (3)(f) He often kisses his wife too the lexical verb kiss remains in place in the VP. In the absence of an auxiliary, however, the tense and agreement features are lowered onto the verb. Sentence (1)(c) ${ }^{*}$ He kisses not his wife is predicted to be ill-formed. This sentence can only be derived by moving the lexical verb kiss out of VP to AGR, so that it appears to the left of the negative element not. This is not allowed on the analysis outlined above. Sentence (3)(c) *He kisses ofien his wife is predicted to be ill-formed for the same reason: in order to derive $(3)(\mathrm{c})$, the lexical verb kiss has to move out of VP to the left of the adverb often. Sentence (2)(c) *Kisses he his wife? is predicted to be ill-formed because the derivation of the sentence would require the lexical verb kiss to be moved out of the VP via $T$ and AGR to $C$. If the auxiliary do were to move to $C$ instead, allowing the lexical verb kiss to remain in the VP, a well-forned sentence Does ke kiss his wife? would be derived, as predicted.

The crucial difference between Afrikaans and French on the one hand, and English on the ther hand, is that in Afrikaans and French lexical verbs must move out of VP to AGR, while in English lexical verbs are prohibited from doing so. Why should this be the case? In a ground-breaking paper Pollock (1989) proposed that the difference results from a difference in parameter values. The parameter in question - let's call it the "agreement (AGR) parameter" - allows the functional category AGR to be associated with an abstract feature which has one of two possible values: [+strong] or [-strong]. In French AGR has the value [tstrong], while in English AGR has the value [-strong]. It is further assumed that is a language with [+strong] AGR, a lexical verb need not be in the VP with its complement in order to mark that complement as being in a certain thematic relation to it (e.g. the relation "the one being kissed" in the sentence He kisses his wife). In a language with [-strong] AGR a lexical verb must be in the VP to mark its complement; it cannot do so from outside the VP. Therefore in English a lexical verb cannot move out of VP to texeive tense and agreement features. If it did so, it would no longer be able to assign a thematic role to its complement. In French a lexical verb can assign a thematic role to its complement from outside the VP. Auxiliaries, by virue of not entering into thematic role relationships with any other constituents in a sentence, are free to occur outside the VP in both French and English. 
As we saw above, Afrikaans patterns like French as far as lexical verb movement is concerned. That is, as in French, lexical verbs can occur outside the VP in Afrikaans. We assume, therefore, that AGR has the same value in Afrikaans as it has in French, i.e. [+strong]. Afrikaans differs from French in another respect, however. Compare the following sentences:

\begin{tabular}{|c|c|c|c|c|c|c|c|}
\hline \multirow[t]{2}{*}{ (11) } & \multirow[t]{2}{*}{$\begin{array}{l}\text { (a) } \\
\text { (b) }\end{array}$} & \multirow{2}{*}{$\begin{array}{l}\text { Elke } \\
\text { *Tous les } \\
\text { every }\end{array}$} & \multirow{2}{*}{$\begin{array}{l}\text { oggend } \\
\text { matins } \\
\text { morning }\end{array}$} & \multicolumn{2}{|c|}{$\begin{array}{l}\text { soen } \quad H Y \\
\text { embrasse-t-IL }\end{array}$} & \multirow{2}{*}{$\begin{array}{l}\text { sy } \\
\text { sa } \\
\text { his }\end{array}$} & \multirow{2}{*}{$\begin{array}{l}\text { vrou. } \\
\text { femme. } \\
\text { wife }\end{array}$} \\
\hline & & & & kisses & he & & \\
\hline & (a) & ${ }^{*}$ Elke & oggend & $H Y$ & soen & sy & rou. \\
\hline & (b) & $\begin{array}{l}\text { Tous les } \\
\text { every }\end{array}$ & $\begin{array}{l}\text { matins } \\
\text { morning }\end{array}$ & $\begin{array}{l}\text { IL } \\
\text { he }\end{array}$ & $\begin{array}{l}\text { embrasse } \\
\text { kisses }\end{array}$ & his & $\begin{array}{l}\text { femme. } \\
\text { wife }\end{array}$ \\
\hline
\end{tabular}

The sentences in (11) and (12) illustrate what happens when a constituent other than the subject - in this case the adverbial expression elke oggend / tous les matins ('every morning') - occupies the initial position in a declarative main clause. In Afrikaans the verb moves to the left of the subject so that it remains the second constituent in the sentence, as shown in (11)(a). If it remains in the position that it normally occupies when the subject is the leftmost constituent in the sentence, an ill-formed sentence results, as shown in (12)(a). In French, by contrast, the word order does not change: the verb remains to the right of the subject where it would have been positioned had the subject been the initial constituent in the sentence, as illustrated by the well-formedness of (12)(b). If the verb moves so as to remain in second position in French, as in (11)(b), the sentence is ill-formed.

The phenomenon illustrated by the Afrikaans sentence (11)(a) is known as the V2 phenomenon. Afrikaans differs from French in being a V2 language. This means that in Afrikaans, unlike in French, the finite verb always occupies the second position in a declarative main clause, irrespective of whether a subject or a non-subject constituent occupies the initial position. The difference between non-V2 languages such as French and V2 languages such as Afrikaans (and other Germanic languages, e.g. German and Dutch) has been claimed to be related to a parametrical difference between these languages as well. A detailed discussion of the parameter in question is beyond the scope of this paper. however. ${ }^{17}$ 


\section{Predictions for L2 acquisition}

The UG Hypothesis claims that interlanguage grammars include parameter settings, just like L1 grammars. The UG Hypotheis therefore predicts that the sentences generated by the interlanguage grammar of an L2 learner will exhibit clusters of properties related to parameter settings - see the discussion in section 2 above. Given that the AGR parameter has the value [+strong) in Afrikaans and French, and the value [-strong] in English, as shown in section 3, the following predictions are made about the gramumars of L2 learners of French who are L1 speakers of English and Afrikaans respectively:

(13) (i) Single clause sentences generated by the interlanguage French grammar of an $\mathrm{L1}$ speaker of English will have either the properties in A. or the properties in B.:

A. Properties predicted by the $\mathrm{L}$ (English) value of the AGR parameter

- Finite lexical verbs occur to the right of the subject in interrogatives.

- Finite lexical verbs occur to the right of sentence-medial adverbs.

- Finite lexical verbs occur to the right of the negative element pas.

B. Properties predicted by the $\mathbf{L 2}$ (French) value of the AGR parameter

- Finite lexical verbs occur to the left of the subject in interrogatives.

- Finite lexical verbs occur to the left of sentence-medial adverbs.

- Finite lexical verbs occur to the left of the negative element pas.

(ii) Single clause sentences generated by the interlanguage French grammar of an L1 speaker of Afrikaans will have the properties in $B$. above which are consistent with both the L1 (Afrikaans) and the L2 (French) value of the AGR parameter.

\section{Data}

\subsection{Subjects}

To test the predictions of the UG hypothesis, data from two L2 learners of French were considered. ${ }^{18}$ The data were collected independently by two postgraduate students, Judy Albrecht and $\mathrm{Zahn} \mathrm{Nel,} \mathrm{as} \mathrm{part} \mathrm{of} \mathrm{their} \mathrm{final} \mathrm{research} \mathrm{projects} \mathrm{for} \mathrm{the} \mathrm{MA} \mathrm{degree} \mathrm{in} \mathrm{General}$ Linguistics at the University of Stellenbosch. 
The first subject is Stephanie, an L1 speaker of English. Stephanie was 12 years old at the time of the study conducted by Albrecht (1998). Stephanie's first exposure to French was at the age of 8 years when she started studying French at school, first in England and then in South Africa. At the time of the study, she was still taking French at school, where she had a French lesson three times a week. She had not yet progressed beyond the beginner's level. She had also been taking more advanced lessons for one hour a week at the Alliance Française for about six months. At school she received explicit grammar instruction, the emphasis was on vocabulary, reading and writing, and English was frequently used in the classroom. At the Alliance the emphasis was on speaking and understanding, explicit instruction was kept to a minimum and English was seldom used. She had had no exposure to French other than at school and at the Alliance.

The second subject, François, is an L1 speaker of Afrikaans, who became bilingual in Afrikaans and German when he lived with his family in Germany between the ages of 6 and 9 years and again between the ages of 12 and 15. His first exposure to French was at the age of 40 years, when he enrolled for French classes at the Alliance Française. At the time of data collection, he had been enrolled at the Alliance for two years and had received approximately 135 hours of instruction in French. The emphasis in the classes was on communication (i.e. speaking and understanding) and contextualized grammar instruction. He had progressed beyond the beginner's level and had entered the intermediate course after one and a half years. At that point his formal instruction ended, but he continued attending bi-monthly conversation classes and had notched up a total of 21 hours in these classes at the time of data collection. He had not had any contact with French other than at the Alliance. Data on François's L2 French are reported in Nel (1998).

\subsection{Data elicitation}

In both cases the data consist of both spoken and written utterances. Stephanie's data consist of spoken utterances produced in the course of three tape-recorded conversations, as well as in a story-telling task and a question task based on a picture sequence. In addition she produced written questions on the basis of another picture sequence, as well as a written paragraph. Finally, she was asked to judge the grammaticality of written sentences containing question words and adverbs, to correct sentences and to rearrange scrambled sets of words to form negative questions.

François's spoken data consist of utterances produced in the course of a 45 minute taperecorded interview during which he talked at length about his life, his work, his family, 
films and music. In addition he was given written tasks which required him to produce or judge negative and interrogative sentences, sentences with relative pronouns, and sentences containing adverbs of time, manner and frequency - a total of 60 written sentences. Finally, he wrote a short paragraph on how he met his wife.

\section{Analysis}

\subsection{Analysis of Stephanie's utterances}

To see whether either of the predicted clusters of properties listed in (13)(i) occur in the French utterances produced by Stephanie, an L1 speaker of English, let us first consider her interrogative utterances. Some representative examples are given in (14). (The finite verb is underlined in each sentence and the subject appears in upper case.)

(14) (a) "Quand ELJE marche à $l$ ' autobus? when she walk to the bus

'When does she walk to the bus(stop)?'

(b) "Quel LES DUPONT mangent pour le diner? what the Dupont eat for the dinner? 'What do the Duponts eat for dinner?'

(c) Qui est LES PARENTS de Danielle? ? $^{\prime 9}$ who is the parents of Danielle 'Who are Danielle's parents?'

(d) Est-ce que MICHELLE visite ses copaines d onze heures? is it that Michelle visits her friends at eleven hours 'Does Michelle visit her friends at eleven o'clock?'

The evidence from interrogatives such as those in (14) is quite clear. Some of the interrogatives produced by Stephanie are derivable on the basis of either a grammar with [-strong] AGR (i.e. her L1 English grammar) or a grammar with [+ strong] AGR (i.e. the L2 French grammar). However, Stephanie also produced interrogatives that are derivable only on the basis of an English grammar, i.e. one that has the [-strong] value of the AGR parameter. (From now on we shall use the expressions "weak AGR" as shorthand for "[-strong] AGR" and "strong AGR" as shorthand for "[+strong] AGR".) Recall that in English weak AGR prevents lexical verbs from occurring to the left of the subject in interrogatives. Only auxiliaries (and the copula) can occur in this position in English. In 
French, by contrast, strong AGR permits both lexical and aluxiliary verbs to occur to the left of (pronominal) subjects in interrogatives. This is true of yes/no questions and questions introduced with a wh-word such as qui ("who"), quand ("when"), pourquoi ("why"), comment ("how"), etc. ${ }^{20}$

Consider the derivation of the following interrogatives: (14)(a) Quand elle marche at l'autobus? and its English equivalent When does she walk to the bus(stop)? and (14)(b) Quel les Dupont mangent pour le diner? and its English equivalent What do the Duponts eat for dinner?. The derivations are shown in (15) below.

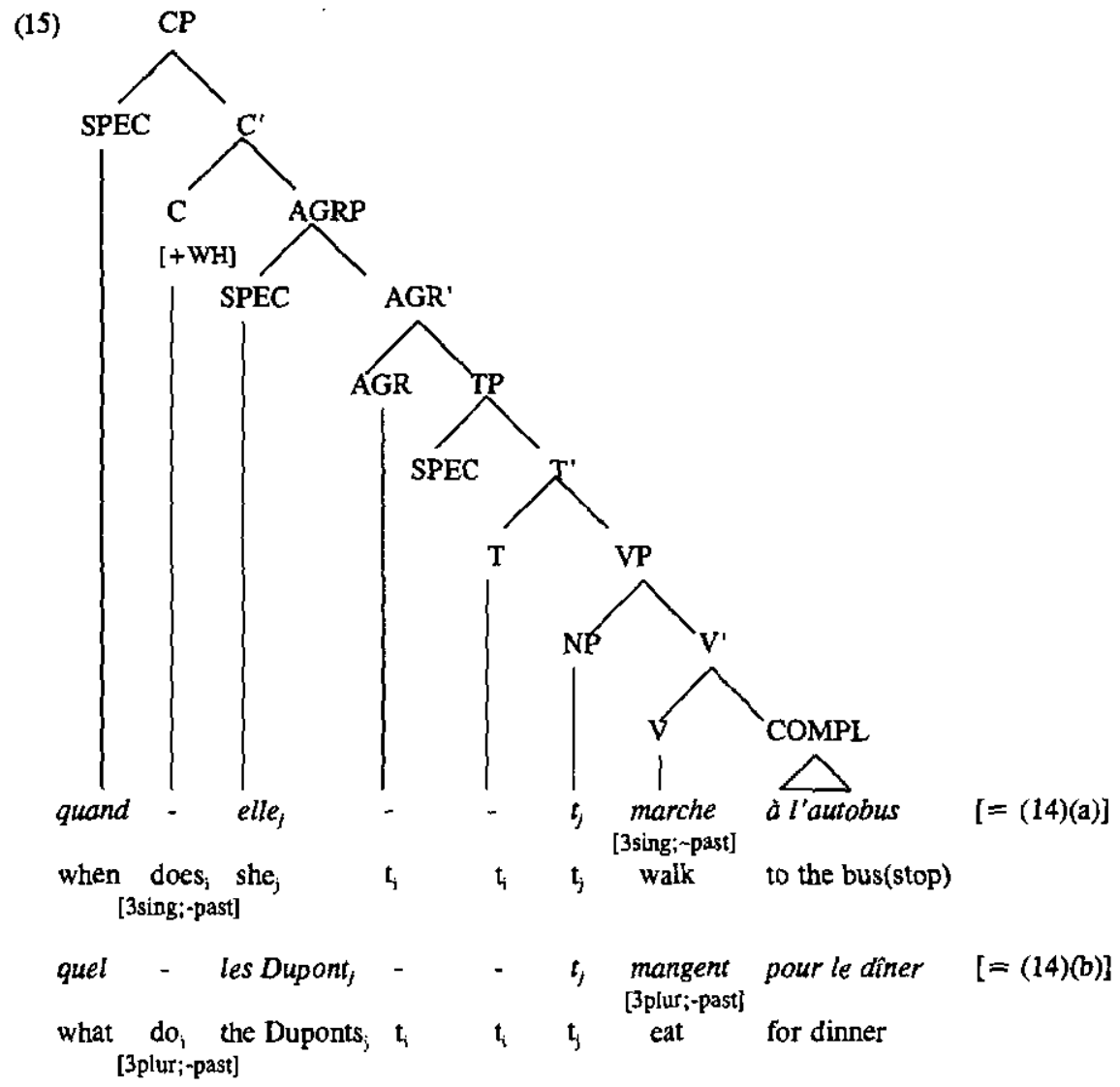


As is clear from (15), Stephanie's interrogative sentences can be analyzed in exactly the same way as the corresponding English ones, i.e. by assuming that the lexical verb does not move out of VP, but that (in the absence of an auxiliary) agreement and tense features are lowered onto the verb. The English solution of inserting do to receive agreement and tense features and to satisfy the interrogative feature [+WH] in $C$ is not available in French. ${ }^{21}$ So, because Stepharie's grammar allows neither lexical verb movement nor do insertion, she ends up producing interrogatives that exhibit exactly the same word order as English interrogatives, but without $d o$.

Only a grammar that permitted lexical verb movement would be able to generate the grammatical equivalents of Stephanie's interrogatives, as is clear from a comparison of the ungrammatical interrogatives in (14)(a)-(b) with their grammatical equivalents in (16)(a)-(b). In (16)(a)-(b) the lexical verb (underlined) has moved past the subject (in upper case) so that it occupies the position to the left of the subject.

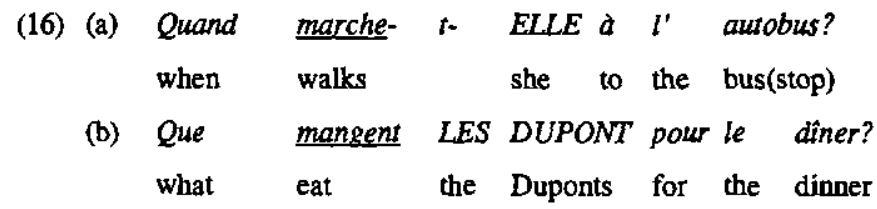

Finally, let us briefly consider the interrogative sentences (14)(c) and (14)(d). Unlike the word order in (14a) and (14b), the word order in both (14)(c) and (14)(d) is possible in French. In (14)(c) it is the copula est ('is') rather than a lexical verb that occurs to the left of the subject. In French, as in English, auxiliaries (and the copula) can move out of VP. In (14)(d) the occurrence of the interrogative formula est-ce que ('is it (the case) that') in sentence-initial position allows the lexical verb visite to remain to the right of the subject Michelle - see note 20. More to the point, however, although the surface word order in both $(14)(c)$ and (14)(d) is acceptable in French, these word orders are derivable on the basis of Stephanie's L1 English grammar as well.

It is worth noting that Stephanie produced target word orders only in interrogatives containing an auxiliary or copula, and in interrogatives introduced by est-ce que. In the judgement tasks she accepted all interrogatives in which the verb followed the subject and no interrogatives in which a lexical verb occurred to the left of the subject. In addition, she 
accepted all interrogatives in which a non-lexical verb (i.e. an auxiliary or copula) occurred to the left of the verb. This too is consistent with the hypothesis that interrogatives in Stephanie's interlanguage French are derived from an English grammar.

If Stephanie produced and judged sentences in French on the basis of her LI English grammar, we would expect her also to produce/accept the following, in accordance with the prediction in (13)(i) above:

(17) (i) sentences in which a finite lexical verb occurred to the right of a sentence-medial adverb, and

(ii) sentences in which a finite lexical verb occurred to the right of the negative pas.

The production data, unfortunately, contain no sentences with sentence-medial adverbs and no negative sentences other than the formulaic $J e$ ne sais pas ('I don't know'). When asked to judge sentences with sentence-medial adverbs, Stephanie behaved as predicted. She accepted all sentences in which the verb occurred to the right of a sentence-medial adverb as in English, e.g. (18)(a) below, and rejected $70 \%$ of sentences in which the verb occurred to the left of a sentence-medial adverb as in French, e.g. (18)(b) below. ${ }^{22}$

$\begin{array}{llll}\text { (18) (a) *Je rarement vois Sophie. } & \text { [Accepted by Stephanie] } \\ \text { I } & \text { seldom see Sophie } & \\ \text { (b) On mange } & \text { souvent des pizzas. } & \text { [Rejected by Stephanie] } \\ \text { one eats } & \text { often some pizzas } & \end{array}$

The adverb data therefore support the hypothesis that Stephanie's interlanguage grammar has the English setting for the AGR parameter.

As far as negatives are concerned, there is very little to go on in the data. As mentioned, Stephanie produced no negative sentences other than Je ne sais pas ('I don't know') in spontaneous conversation. Je ne sais pas is an expression that occurs with regular frequency in the classroom and which, according to Albrecht (1998: 29), she has probably learnt by heart as a formulaic, i.e. unanalyzed, form. The only other negative sentences in the data were produced in response to a task in which she was given unordered sets of words with the instruction to arrange the words to form questions beginning with ne. All the negative questions produced in response to this task had the form shown in the (i)-sentences in (19), instead of the target form shown in the (ii)-sentences: 

(19) (a) (i) *Ne connais pas tu cette fille? know not you this girl
(ii) Ne connais- tu pas cette fille? know you not this girl
(b) (i) *Ne vont pas ils en Amérique? go not they to America
(ii) Ne vont-ils pas en Amérique? go they not to America

Negative questions such as those produced by Stephanie and exemplified in the (i)-sentences in (19) conform to neither the English nor the French grammar. They cannot be generated by the English grammar, because finite lexical verbs (such as connais and vont) are not allowed to move out of VP and past the negative pas in terms of this grammar. They cannot be generated by the French grammar, because the subject has to appear in the specifier position of AGRP, i.e. to the left of the negative pas, in terms of this grammar. (See the tree diagram in (5) above for the derivation of negative sentences in English and French.)

A possible explanation for the occurrence of these sentences in the data suggests itself when we consider the task which gave rise to their occurrence. Recall that outside of this task, Stephanie produced only one negative expression, viz. je ne sais pas. It was claimed above that for Stephanie this is probably a formulaic expression, i.e. an expression that she learned as a frozen (or unanalyzable) unit. The implication would be that she did not know yet how negative sentences are formed in French. When pressed to form questions starting with ne, she had only one option: she hypothesized on the basis of her knowledge of the expression je ne sais pas that negative verbs in French have the form ne+V+pas. The task required her to start each negative question with ne. Having hypothesized that ne+V+pas formed an unanalyzable unit, she therefore started every sentence with the entire expression $n e+V+p a s$. This resulted in the word order ne+V+pas - subject - complement manifested in the sentences in (19).

Given this, admittedly speculative, account of the occurrence of negative questions such as the ones in (19) in the data, no conclusions can be drawn from their occurrence about the nature of Stephanie's interlanguage grammar. Crucially, the occurrence of these forms cannot be taken as counterevidence to the claim that she relies on her L1 English grammar to construct sentences in her L2 French. 
Finally, let us briefly consider the declarative sentences produced by Stephanie to see whether they can be analyzed in a way that is consistent with the claim that Stephanie's interlanguage grammar contains the $\mathrm{LI}$ value of the AGR parameter. The declarative sentences in $(20)$ are representative of the declaratives produced by Stephanie. (The finite verb is underlined in each case.)

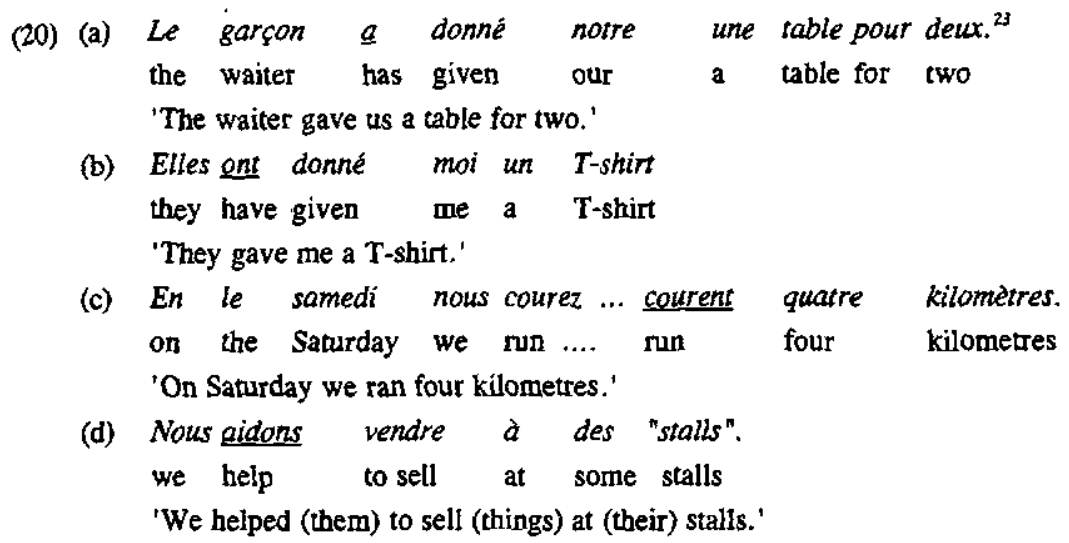

The declaratives in (20) can be analyzed as having exactly the same derivation as the corresponding English sentences, as is clear from the representation in (21) of the derivation of (20)(b) Elles ont donné moi un T-shirt and its English equivalent They have given me a $T$-shirt, and of (20)(c) (En le samedi) nous courent quatre kilometre and its English equivalent (On Saturday) we ran four kilometres. (The feature $[-\mathrm{WH}]$ in (21) indicates that the sentence is non-interrogative.) 
(21)

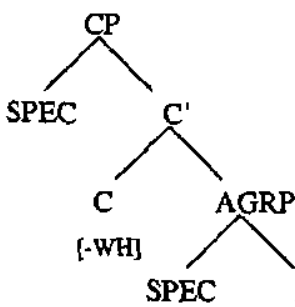

SPEC

AGR'

\{

GR<smiles>CC(C)[SeH2]</smiles>

SPEC

elles, ont

they have $_{i}$ [3plur;-past]

NEG

TP

SPEC

(en samedi)

nous

(on Saturday) we $\mathrm{w}_{\mathrm{j}}$ -

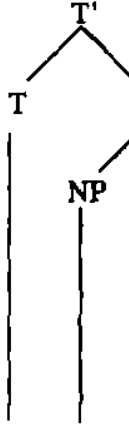

$t_{1} t_{\text {t donné }}$

t $\mathbf{t}$ given

- $t_{j}$ couren

$\mathbf{t}_{\mathrm{j}}$ ran [1plur; + past]

Note that the sentence $(20)$ (c) (En samedi) nous courent quatre kilometres would also be compatible with a derivation on which, as in French, the finite lexical verb courent moved to AGR via $\mathrm{T}$ to obtain tense and agreement features, instead of remaining in $\mathrm{V}$ and having the features lowered onto it as in English. The difference between these two derivations is not visible in the surface word order. Similarly, the difference between a derivation on the basis of an English grammar and a derivation on the basis of a French grammar is not visible in the case of sentences such as (20)(b) in which the finite verb is an auxiliary verb 
instead of a lexical verb. So, although the word orders in the French declarative sentences in (20) could be derived on the basis of a grammar with strong AGR (i.e. the target French grammar), these word orders are equally consistent with a derivation on the basis of a grammar with weak AGR (i.e. Stephanie's L1 English grammar).

An analysis of Stephanie's utterances has shown them to exhibit the cluster of properties listed in A. in (13)(i). The only utterances that do not exhibit the predicted properties are a small number of negative utterances which she produced in a written task and for which an alternative account was suggested. It can be concluded that her interlanguage grammar includes the [-strong] value of the AGR parameter. Her declarative utterances too were shown to be consistent with this clain.

\subsection{Analysis of François's data}

Let us turn now to an analysis of the French utterances produced by the second subject, François, whose L1 is Afrikaans, to see whether these utterances too provide evidence for the presence of a value for the AGR parameter in the underlying interlanguage grammar. Recall that French and Afrikaans are assumed to have the same setting for the AGR parameter, viz. AGR has the value [+strong]. Therefore, whether François's interlanguage grammar contains the (transferred) L1 value of the AGR parameter, or the (acquired) L2 value, the 'prediction is that the French sentences produced by François will display the cluster of properties associated with strong AGR, i.e. the properties listed in B. in (13)(i) above.

A first prediction of the claim that the interlanguage grammar includes the strong value of the AGR parameter is that finite lexical verbs will occur to the left of the subject in interrogative sentences. A representative sample of the interrogative sentences produced or judged to be acceptable by François is given in (22). (The finite verb is underlined and the subject appears in upper case.)

(22) (a) Crois - TU que le film européen est meilleur que le film américain? believe you that the film European is better than the film American 'Do you believe that European films are better than American films?'

(b) Rencontre -t $-I L$ vraiment beaucoup de gens? meets he really many of people 'Does he really meet many people?' 
(c) '스 JEAN assez d' argent? has Jean enough of money 'Does Jean have enough money?'

(d) "Quand partent TES AMIS? when leave your friends

'When do your friends leave?'

In all the interrogative sentences which François produced or judged to be acceptable, the verb occurs to the left of the subject, as exemplified in (22). This is in accordance with a [+strong] setting for the AGR parameter. The derivation of the interrogatives in (22)(a) and (d), as well as their Afrikaans equivalents, is shown in (23).

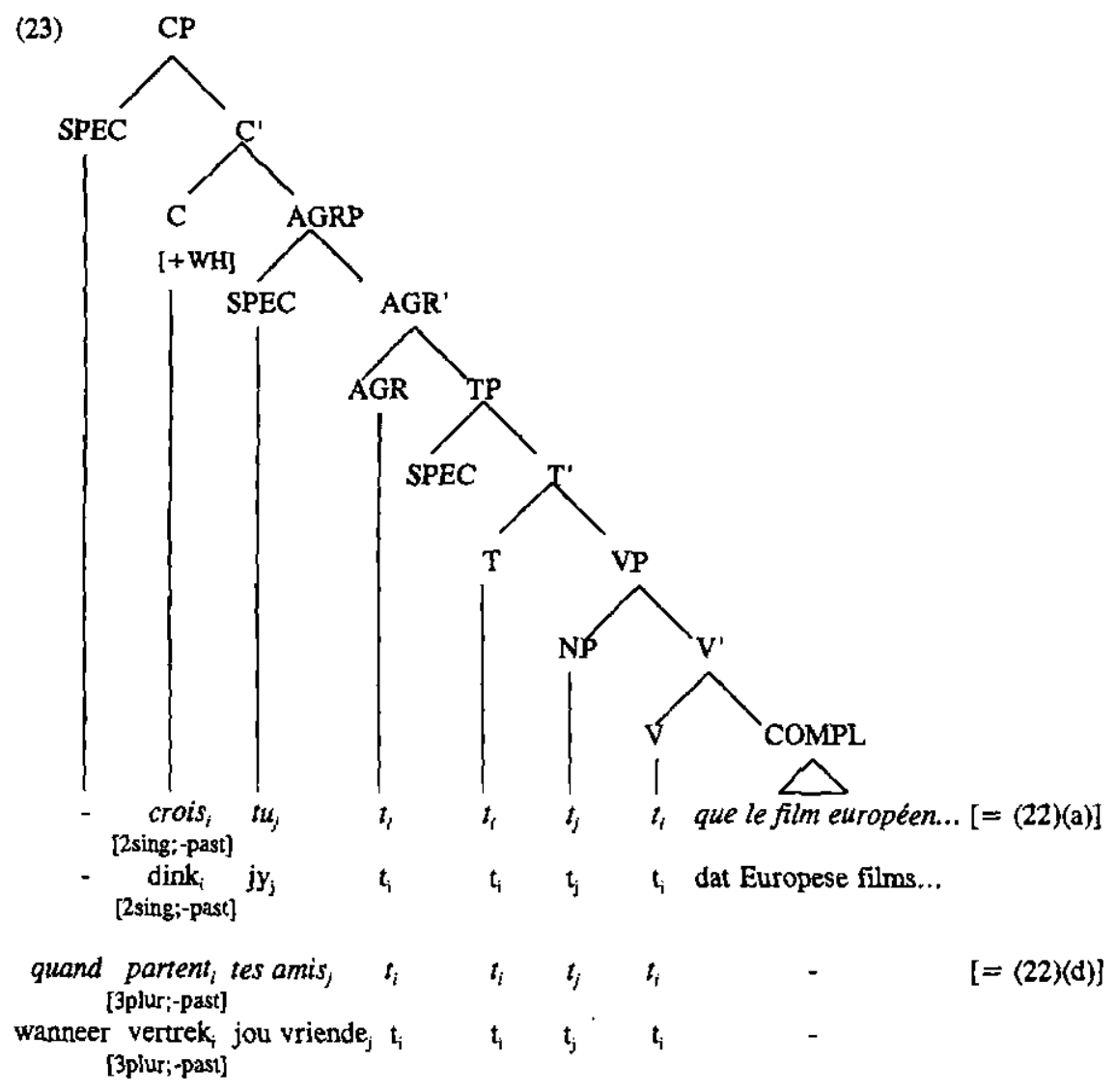


Only a grammar that permits lexical verb movement can generate the interrogatives in François's data. In (22)(a) and (d) (as well as in (22)(b) and (c) for which the derivation is not shown) the finite lexical verb has moved past the subject so that it occupies the position to the left of the subject. Note that $(22)(c)$ and (d) are ungrammatical in French. Yet François accepted both in a judgement task. The ungrammaticality of (22)(c) and (d) has nothing to do with the value of the AGR parameter, however. The ungrammaticality of these sentences has to do with a property of French which is unrelated to the AGR parameter, viz. the restriction on the inversion of verbs and non-pronominal subjects in French - see note 20 above. It can be concluded, therefore, that François's interlanguage grammar includes the [+strong] value for the AGR parameter in terms of which all the interrogatives in (22) are well-formed, but that the grammar does not yet include knowledge of the restriction on inversion between verbs and non-pronominal subjects in French.

A second prediction of the claim that the interlanguage grammar includes strong AGR is that lexical verbs should occur to the left of sentence-medial adverbs in utterances produced or judged to be acceptable by François. François produced the following utterances with sentence-medial adverbs during spontaneous conversation. (Finite verbs are underlined and adverbs are in upper case in the examples.)

$\begin{array}{rll}\text { (24) (a) Je déteste TOTALEMENT le musique populaire. } & \\ \text { I detest completely the music }\end{array}$ 'I completely detest popular music.'

(b) Je aime BEAUCOUP la musique réligieuse. I like much the music religious 'I like religious music a lot.'

(c) Rencontre-t-il VRAIMENT beaucoup de gens? [=(22)(b)] meets he really many of people 'Does he really meet many people?'

In an adverb placement task he produced the following utterances: 
(25) (a) Le chat aime FOLLEMENT le poisson.

the cat loves madly the fish

'The cat is mad about fish.'

(b) On rencontre RAREMENT les dinosaurs.

one meets rarely the dinosaurs

'One rarely comes across dinosaurs.' ${ }^{24}$

It is clear from the examples provided that François's utterances have the predicted property: the finite lexical verb appears to the left of the adverb. As sentence-medial adverbs are assumed to occur to the left of V in VP (see Radford 1997: 371) the occurrence of the verb to the left of the adverb is an indication that the verb has moved out of VP.

Finally, let us consider François's negative utterances. François spontaneously produced almost thirty negative utterances. He was also given a written task in which he was required to change positive sentences into negative ones. With three exceptions, the spontaneously produced negatives were Je ne sais pas ('I don't know'), Ge n'est pas ('It isn't'), Je ne suis pas ('I'm not'), Je n'ai pas ('I don't have') or Il n'y a pas ('There is/aren't'). Examples are provided in (26). (Finite verbs are underlined and the negative appears in upper case.)

(26) (a) Ce $n^{\prime}$ est PAS nécessaire de être religieuse.

it is not necessary to be religious

'It isn't necessary to be religious.'

(b) Je ne suis PAS religieuse.

I am not religious

'I'm not religious.'

(c) Je ne sais PAS si tu as entendu?

I know not if you have heard

'I don't know whether you've heard.'

(d) Il n' $\quad$ y $\quad$ a PAS beaucoup de bons films.

it there have not many of good films

'There aren't many good films.' 
(e) Je $n^{\prime}$ ai $P A S$ une préférence.

I have not a preference

'I don't have a preference.'

In addition to negative utterances such as those exemplified in (26), François spontaneously produced the following negative utterances:

(27) (a) Je ne sens JAMAIS que $c^{\prime}$ est le cas.

I feel never that it is the case

'I never feel that it is the case.'

(b) Je n' ai JAMAIS le sens que $j^{\prime}$ ai accompli assez. I have never the feeling that I have accomplished enough 'I never have the feeling that I have accomplished enough.'

(c) ....si je suis heureux si je ne travaille PAS?

....whether I am happy if I work not

'... whether I'm happy if I don't work?'

In all the utterances in (26) and (27) the verb occurs to the left of the negative element. Only utterances containing a finite lexical verb are relevant to the question of whether or not negative utterances produced by François provide evidence for the claim that his interlanguage grammar contains strong AGR. Recall that non-lexical verbs, i.e. auxiliaries and the copula, are expected to occur to the left of the negative element even in languages such as English which have weak AGR. All François's negative utterances with finite lexical verbs, i.e. $(26)(\mathrm{c}),(26)(\mathrm{e})$ and $(27)(\mathrm{a})$, moreover, are derivable on the basis of a grammar containing the [+strong] value for the AGR parameter.

The derivation of two representative examples of negative utterances containing lexical verbs is given in (28) below. Both utterances are derived by moving the lexical verb out of VP to $A G R$ via $T$ and NEG. The negative clitic ne, which originates in NEG, prefixes to the verb in NEG and moves with it to AGR. The verb further acquires tense features in $T$ and agreement features in AGR. The subject moves from the specifier position in VP to the specifier position in AGRP. 
(28)

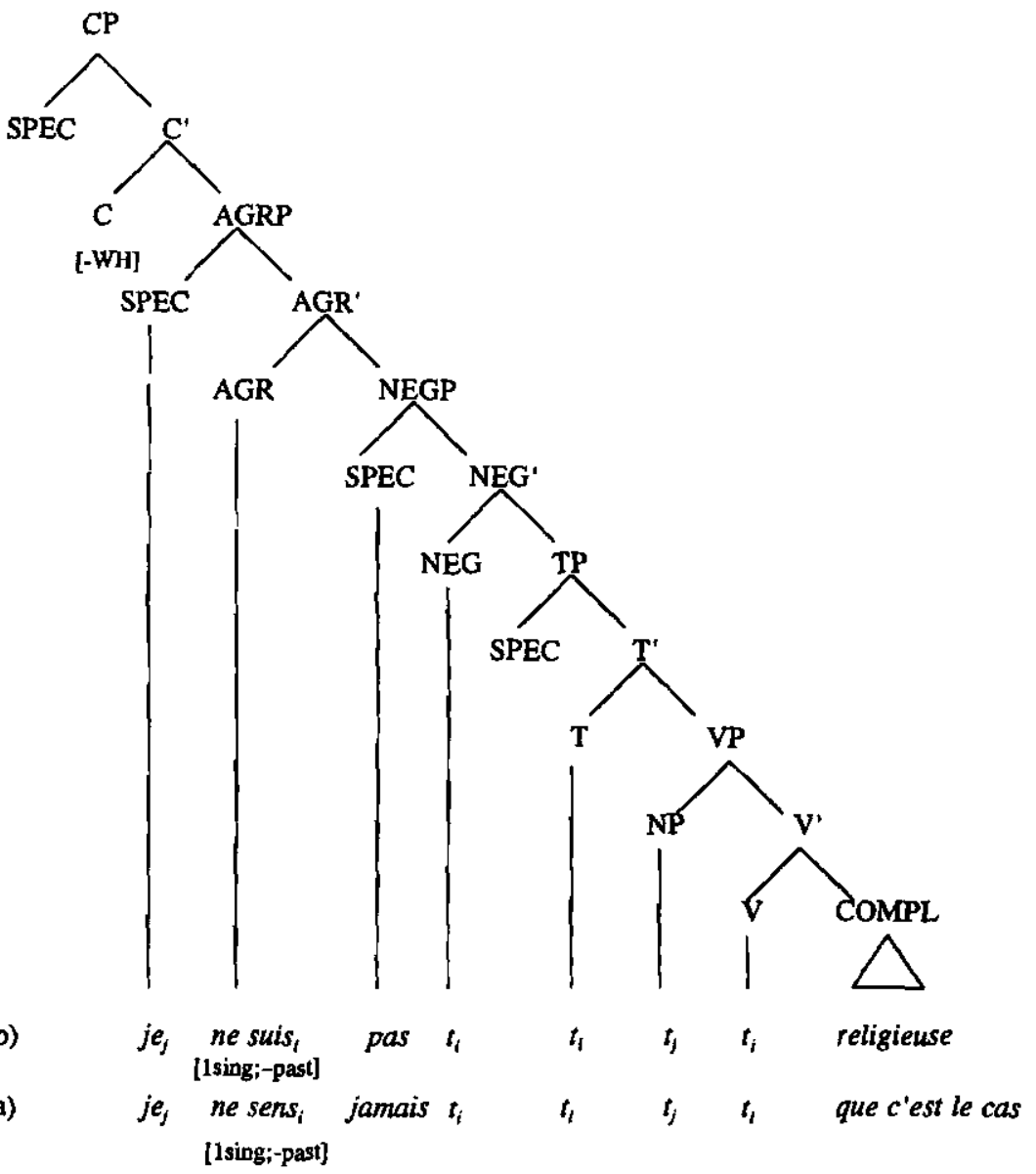

It would seem as though François's negative utterances provide further support for the claim that his interlanguage grammar includes the strong value of the AGR parameter. In the written task, however, he produced the following two ungrammatical utterances.

(29) (a) *Ne visites $\mathrm{PAS}$ tu le musée? visit not you the museum

'Don't you visit the museum?'

(b) *Ne veux $P A S$ tu visiter le musée? want not you visit the museum

'Don't you want to visit the museum?' 
Although the lexical verb occurs to the left of the negative element pas in these utterances, as required, the occurrence of the subject to the left of the negative element pas is problematic. Recall that Stephanie produced similar negative utterances - see (19) above. As in the case of Stephanie's utterances, I would like to argue that the occurrence of utterances such as those of (29) is the result of a misanalysis of ne+V+pas. Like Stephanie, François assumes that ne+V+pas is an indivisible unit in French. This unit may be inserted fully formed into Dstructure, or it could be formed through the simultaneous cliticization of ne and pas to the verb in NEG, in which case ne and pas presumably are assumed by François to be a single discontinuous clitic which is circumfixed to the verb in NEG. If ne and pas form a unit with the verb, it follows that the entire unit should move to $\mathrm{C}$, i.e. past the subject, in questions such as those of (29). The derivation in terms of which ne and pas both cliticize to the verb in NEG is shown in (30).

(30)

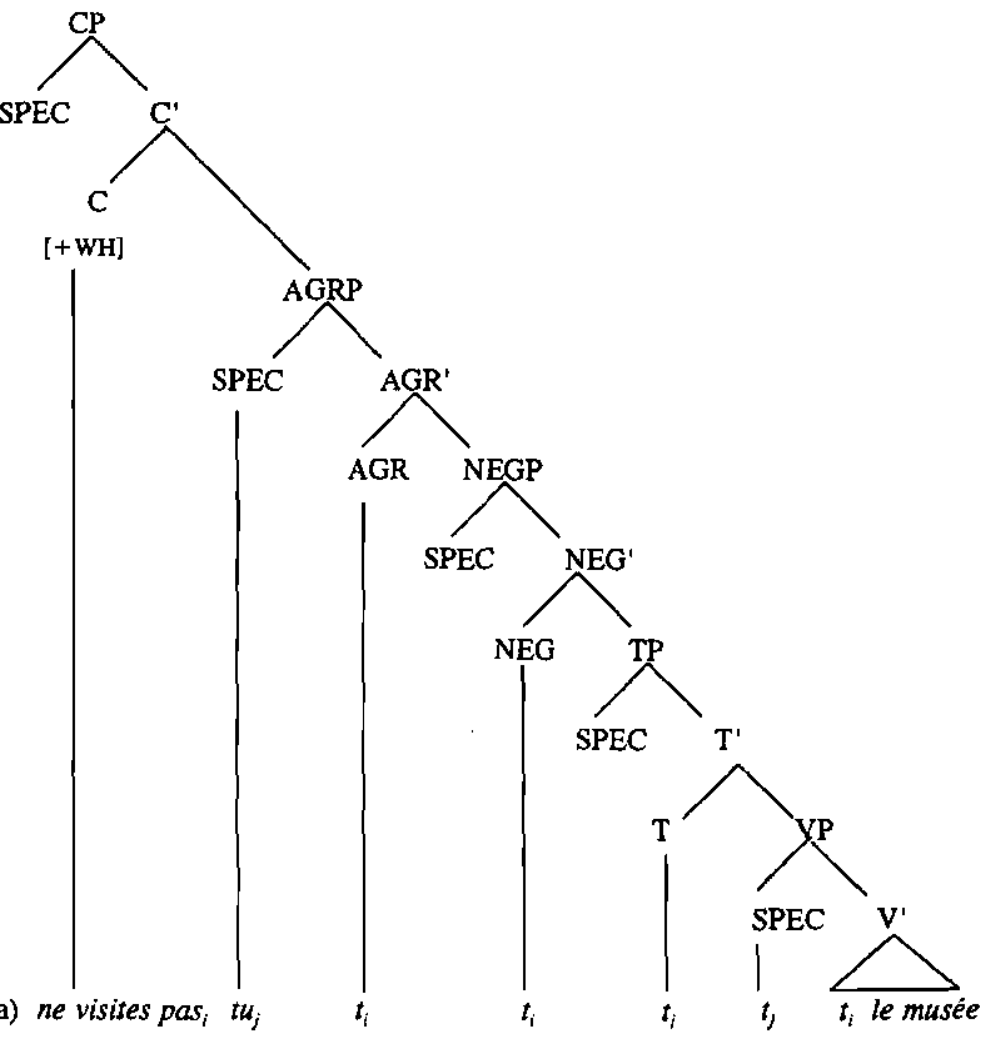

[2sing;-past] 
There is some evidence for the assumption that François, like Stepharie, misanalyzes ne and pas as constituting a single discontinuous element which cliticizes to the verb. Note that by far the majority of François's spontaneously produced negative utterances were $j e$ ne sais pas ('I don't know'), or equally high-frequency expressions such as je ne suis pas (I am not'), je n'ai pas ('I don't have'), and ce n'est pas ('it isn't'), with one occurrence of the highly idiomatic phrase il n'y a pas ('there is/aren't') - see (26) above. It could well be that François acquired these expressions as fixed expressions and consequently hypothesized that negation entailed simultaneous cliticization of both ne and pas to the verb. Additional support for this account is provided by the following negative utterances which François produced in the written task.

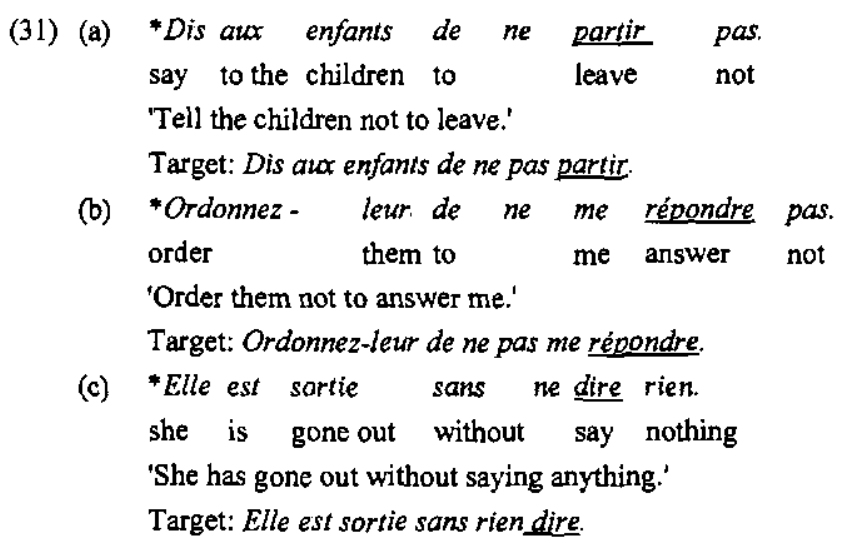

When the verb is in the infinitive in French, it remains to the right of the negative element, as shown in the target sentences in (31). The fact that François consistently places all negated verbs between ne and pas (or rien in the case of (29)(c)), is consistent with the hypothesis that he assumes negation to entail simultaneous cliticization of $n e$ and pas to the verb. Note that even in $(29)(\mathrm{c})$, where no $n e$ is required, François has added both ne and rien to the verb.

Given this account of the way in which François treats ne ... pas, the grammatical negative utterances in (26) and (27) should have the analysis shown in (32), instead of the analysis shown in (28) above. On the analysis in (32) ne and pas both cliticize to the verb in NEG, so that ne+V+pas moves to AGR as a unit. Note that the analysis in (32) is no less consistent with the claim that the interlanguage grammar allows finite lexical verbs to occur to the left of the negative element. 


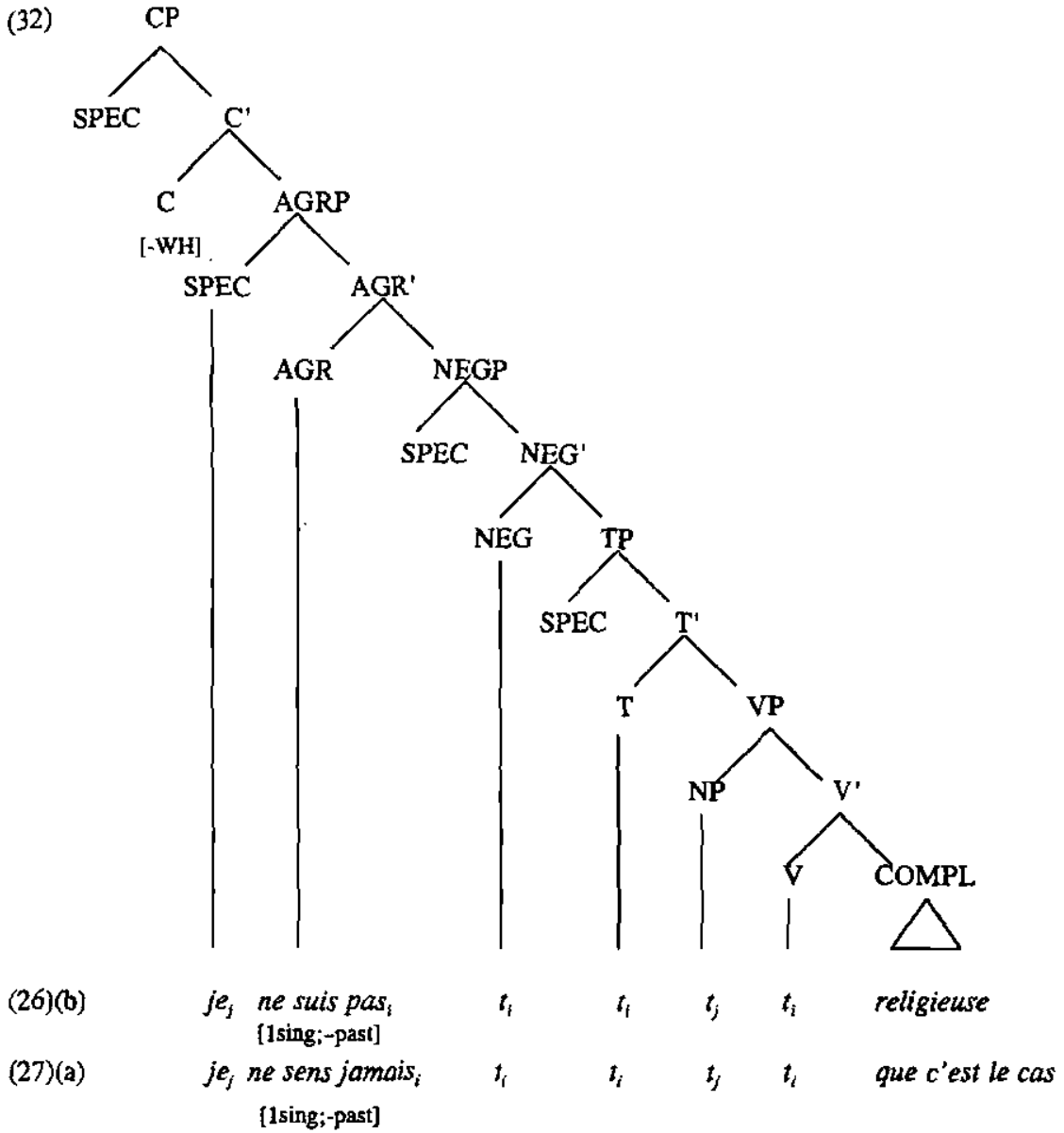

It can be concluded from the analyses proposed above that François's utterances exhibit the full cluster of properties predicted by the claim that his interlanguage grammar contains the [+strong] setting for the AGR parameter. It is not possible to say whether the interlanguage parameter setting reflects a transferred L1 setting or an acquired L2 setting, as the setting is the same in the L1 and the L2. It is interesting to note, however, that François's interlanguage grammar at the time of the study did already exhibit at least one $L 2$ property, viz. the absence of V2. To see this, compare François's utterances in (i) with the corresponding Afrikaans sentences in (ii) in (33). 
(33) (a) (i) Hier je suis allé au cinéma. yesterday I was gone to the cinema 'Yesterday I went to the cinema.'

(ii) "Gister ek het fliek toe gegaan. yesterday I have cinema to gone Gister het ek fliek toe gegaan.

(b) (i) Demain nous voulons partir. tomorrow we want to leave 'Tomorrow we want to leave.'

(ii) "Môre ons wil vertrek. tomonow we want to leave Môre wil ons vertrek

It is clear from a comparison of François's French utterances with the corresponding grammatical Afrikaans utterances in (33) that his interlanguage grammar no longer contains the L1 setting of the parameter responsible for the V2 phenomenon in Afrikaans. In his utterances the finite verb consistently appears to the right of the subject (i.e. in AGR), and not in second position as it does in the corresponding Afrikaans sentences. This may be taken to indicate that some parameter resetting from L1 to L2 values had already occurred in Francois's interlanguage grammar at the time of the study. It would therefore not be unwarranted to conclude that he had also in fact acquired the L2 setting for the AGR parameter. In this case the fact that his utterances exhibited the properties associated with the [+strong] value of this parameter was the result, not of transfer from his L1 Afrikaans, but of acquisition of the target L2 parameter setting.

\section{Discussion and conclusions}

The analyses in the previous section have shown both Stephanie's and François's French utterances to exhibit clusters of properties related to the AGR parameter. Stephanie's utterances have been shown to exhibit the cluster of properties in (13)(i)A. above - repeated here as (34) - while François's utterances have been shown to exhibit the cluster of properties in (13)(i)B. - repeated here as (35).

\section{(34) Properties predicted by the L1 (English) value of the AGR parameter}

- Finite lexical verbs occur to the right of the negative element pas.

- Finite lexical verbs occur to the right of the subject in interrogatives.

- Finite lexical verbs occur to the right of sentence-medial adverbs. 
(35) Properties predicted by the L2 (French) value of the AGR parameter

- Finite lexical verbs occur to the left of the negative element pas.

- Finite lexical verbs occur to the left of the subject in interrogatives.

- Finite lexical verbs occur to the lefi of sentence-medial adverbs.

In section 2 it was argued that the occurrence of a cluster of properties related to a parameter in the utterances of an L2 learner would be an indication that the acquisition of the L2 was mediated by UG. Stephanie's utterances were shown to exhibit all the properties related to the [-strong] value that the AGR parameter has in her L1 English. François's utterances were shown to exhibit all the properties related to the [+strong] value that the AGR parameter has in both Afrikaans, his L1, and French, his L2. Both L2 learners can therefore be argued to have been constructing sentences in their L2 on the basis of an interlanguage grammar that includes a parameter of UG. That is, they were not acquiring the properties of the L2, i.e. the various positions in which finite lexical verbs can occur in the L2, one by one in a piecemeal fashion. This could have been argued to be the case had Stephanie's or François's utterances been found to exhibit a mixture of the properties in (34) and (35).

No firm conclusions can be drawn from the results of the analyses in section 6 about the question of whether UG is actively involved in L2 acquisition (the parameter-triggering version of the UG Hypothesis), or whether UG is present through the L1 grammar, but essentially inactive (the parameter-transfer version of the UG Hypothesis). The conclusion that UG is actively involved would require evidence that parameter values have been reset from the $\mathrm{L} 1$ value to some non-L1 value (which could, but need not, be the $\mathrm{L} 2$ value - see, e.g., White 1992: 229). Data that demonstrate only the operation of the L1 value of a parameter give no indication as to whether UG is active or inactive in the construction of the interlanguage grammar.

Stephanie's interlanguage grammar was found to contain the $L 1$ value of the AGR parameter. Only a follow-up study will indicate whether or not the AGR parameter has been reset to its L2 value in her interlanguage grammar, i.e. whether or not UG is actively involved in her acquisition of French as an L2. François's interlanguage grammar could have contained either 
the $\mathrm{Ll}$ or the $\mathrm{L} 2$ value of the AGR parameter, as the $\mathrm{L} 1$ and $\mathrm{L} 2$ grammars are indistinguishable in this respect.

The only indication that UG might be actively involved in François's acquisition of French as an $\mathrm{L} 2$ is that his interlanguage grammar seems to contain the L2 rather than the L1 value of the parameter responsible for the difference between V2 and non-V2 languages. We reached this conclusion on the basis of only one property of François's L2 utterances, however, viz. the fact that finite lexical verbs do not occur in second position in utterances containing a nonsubject constituent in the sentence-initial position - see (33) above. Ideally, one would want to show that François's utterances exhibit a cluster of properties that are all related to the parameter value in question. The presence of the full cluster of properties related to the L2 value of the parameter would constitute strong evidence for the claim that the parameter has indeed been reset to this value. This is a matter for further research.

To summarize: the L2 utterances of two L2 leamers of French were shown to exhibit the full cluster of properties related to one or the other value of the AGR parameter. From this we concluded that both leamers' interlanguage grammars included the parameter in question. These learners could therefore be argued to have been constructing a grammar for their L2, rather than to be learning the properties of the $\mathrm{L} 2$ one by one in a piecemeal fashion. It is not possible, however, to provide an answer to the question of whether UG is actively involved in the construction of the interlanguage grammar, or whether it is merely (passively) present as a constraint on the interlanguage grammars that can be constructed by L2 learners. In order to provide an answer to this question, evidence would have to be presented showing either that parameter-resetting can or that it cannot occur in $\mathrm{L} 2$ acquisition.

\section{Some implications for $\mathbf{L} 2$ teaching}

The study of Stephanie's and François's L2 French utterances reported here raises some points of interest to $\mathrm{L} 2$ teachers. The finding that François might already have progressed beyond the L1 grammar and have acquired aspects of the L2 grammar, while Stephanie seems still to have been stuck with her $\mathrm{L} 1$ grammar at the time of the study, raises interesting questions about the role of age in L2 acquisition. Recall that François was 40 years old when he started learning French, whereas Stephanie was first exposed to French at the age of 8 . This would 
seem to call into question the widely held belief that younger, specifically pre-pubertal, L2 learners are more successful than older, i.e. post-pubertal, ones. It would certainly seem at a first glance as though François's age is not an inhibiting factor in his acquisition of French as an L2. However, one should be careful not to take the difference in initial rate of progress between him and Stephanie as an indication that he will eventually be more successful at learning French than Stephanie. There is ample evidence in the L2 literature that, although older L2 learners are often more successful initially, they are invariably surpassed by younger leamers in the long run. ${ }^{25}$

A related point concerns the type of input received by the two learners. Recall that French subject classrooms at the different schools that she attended were Stephanie's sole source of L2 input. Her instruction had been mostly formal, with explicit emphasis on the grammar and vocabulary rather than the use of the L2. She had only been attending communicationoriented classes at the Alliance Francaise for approximately six months at the time of the study. François, by contrast, had studied French only at the Alliance Française where the emphasis was on using the language, rather than on learning about the grammar of the language. The difference in the results of the two types of input are quite striking. Stephanie was still stuck with her Ll grammar after four years of instruction, while François, after only two years, had already progressed beyond the $\mathrm{L} l$ grammar.

A last point worth commenting on is the fact that both learners independently produced what would seem to be a highly idiosyncratic sentence type, viz. ungrammatical negative questions such as *Ne visites pas tu le musée? (produced by François - see (29) above) and *Ne connais pas tu cette fille? (produced by Stephanie - see (19) above). Recall that the explanations provided for the presence of this sentence type in Stephanie's and François's data respectively were partly similar, but also partly different. In both cases it was hypothesized that the expression ne+V+pas had been leamed as a fixed expression or frozen form as a result of the high frequency with which expressions such as je ne sais pas ('I don't know'), ce n'est pas ('it isn't'), je n'ai pas ('l don't have'), etc. occurred in the input. The difference is that François treated negative expressions of the form ne+V+pas in exactly the same way as all other verbs, moving them to the left of the subject in interrogative sentences in accordance with his interlanguage grammar. Stephanie, by contrast, placed these negative expressions to 
the left of the subject in questions, in violation of her interlanguage grammar, only because she was left with no other option by the instruction that she had been given.

This analysis raises two points worth mentioning. The first is that similar "errors" often have different causes and should therefore be addressed differently. Efforts to correct the "error" committed by Stephanie and François would have to make provision for the different sources of the error in the two cases. Franfois would only need to realize that ne+V+pas is not an unanalyzable expression. Having realized that only ne cliticizes to the verb and that pas is a separate non-clitic element in the specifier position of NEGP, he will automatically produce correctly formed negative questions, i.e. questions in which only ne+V occurs to the left of the subject, as in (28) above. The realization that ne+V+pas is an analyzable expression will not help Stephanie, though. She also has to realize that the AGR parameter has different values in French and English before she will be able to produce target-like negative questions spontaneously in French.

The second point has to do with a phenomenon first identified by Selinker (1972) and referred to as "transfer of training" ${ }^{26}$ L2 teachers need to be aware of the potentially negative effect of the frequent occurrence of linguistic forms in the L2 classroom - often, but not always, as a result of drilling or pattern practice. It was suggested above that the frequent occurrence of expressions such as je ne sais pas ('I don't know'), ce n'est pas ('it isn't') and je n'ai pas ('I don't have') in the input which leamers receive may cause them inadvertently to acquire the structure underlying these expressions, i.e. ne+V+pas, as an unanalyzable unit or frozen form. This, it was hypothesized, is what caused the occurrence of the ungrammatical negative questions in François's and Stephanie's utterances.

Finally, I hope to have shown that careful linguistic analysis of L2 learners' utterances can lead to sometimes quite unexpected insights into the reasons why these utterances occur: insights which may help L2 teachers to be more effective in their role as facilitators of L2 acquisition. 


\section{NOTES}

1 Some authors refer to a language which is not spoken in the community in which it is being learned as a "foreign language", and to a language which is spoken in the community as a "second language". This distinction is irrelevant to the concerns of this paper.

2 The distinction between "acquisition" and "learning" was first made by Krashen. He uses the term "acquisition" to refer to unconscious internalization of knowledge, and "learning" to refer to conscious internalization of knowledge - see Krashen (1985).

3 For an account of the arguments for an innate UG and details of the UG-based view of L1 acquisition, see e.g. Botha (1995: par. 4.3), Cook and Newson (1996: ch. 3), Jackendoff (1994: ch. 3), or White (1989: ch. 1).

4 Another, related view is that of Felix (1987) who argues that, once the general problem-solving cognitive system has matured, it competes with UG in the processing of linguistic input for purposes of language acquisition. The result is that $\mathrm{L} 2$ learners tend to make use of their problem-solving cognitive system rather than UG, although UG is still available.

s The Universal Grammar representing the child's innate knowledge, or initial state, is claimed to comprise a number of sub-systems of principles, each associated with one or more open parameters with variable settings. To give a simple example: it is assumed that UG contains a word order principle which states, roughly, that heads of phrases (for example verbs and nouns) occur in a fixed order with respect to their complements. The two possible orders, head-complement ot complement-head, constitute the possible values of the parameter associated with the word order principle. For example, the head position parameter is commonly assumed to have the value 'head-final' in Afrikaans and the value 'head-initial' in English. This difference is responsible for the fact that complements precede the verb in Afrikaans, while they follow the verb in English, as shown by the following contrast:
AFRIKAANS:
dat sy dikwels die werkwoord in die verkeerde posisie plaas
that she often the verb in the wrong position places

COMPL COMPL $\mathrm{V}$

ENGLISH:

that she often places the verb in the wrong position

V COMPL COMPL


What happens in the course of $\mathrm{Ll}$ acquisition is that the values for the open parameters are fixed on the basis of features of the linguistic input which the child receives. The child must only determine on the basis of the evidence, or input, she is exposed to what the value of the parameter is for that language. The $\mathrm{L} 1$ grammar, then, consists of UG principles, parameter settings for the L1, and grammatical properties of the L1 that are not related to UG, such as the lexical items of the language.

6 Epstein et al. (1996) present an extensive critical discussion of the different hypotheses about the role of UG in L2 acquisition. Their categorisation of the different positions differs from the one presented here, though. As pointed out by numerous commentators, their categorisation and critique is based on an inaccurate representation of some researchers' positions. See, e.g., the commentaries by BleyVroman, Borer, Gregg, Vainikka and Young-Scholten and White in Epstein et al. (1996).

See Atkinson (1992: ch. 8) for an argument to the effect that there is in fact no qualitative difference between parameter-triggering and hypothesis formation.

8 See Botha (1989: par. 2.4) for some discussion of the differences between the pre- and post-eighties UG theory of $\mathrm{Ll}$ acquisition.

- The new value of the parameter need not be the target $L 2$ value. Remember that at the start of L2 acquisition (at least some of) the parameters are set to their L1 values. White (1989: ch. 6) argues that different types of evidence may be required to reset a parameter in L2 acquisition than are required to set a parameter in L1 acquisition. The required evidence may not be present in the $\mathrm{L} 2$ input to which the learner is exposed. This may result in retention of the L1 parameter or even resetting of the parameter to a value which is appropriate for neither the $\mathrm{L} 1$ nor the $\mathrm{L2}$, but which is nevertheless made available by UG.

10 The choice of theoretical framework was motivated by the focus of the paper. The concept of clusters of properties related to parameter values does not feature as prominently within the more recent version of generative syntactic theory (known as the Minimalist Program) as it does within the older Government and Binding version.

11 It is a characteristic of lexical verbs that they enter into role relationships with the noun phrases in a sentence. For example, in the sentence He has kissed his wife the lexical verb kiss describes an event with two participants, He (the "kisser") and his wife (the "kissed"). 
12 The auxiliary verb has and the inflectional morpheme -ed in the sentence He has kissed his wife - see note 11 - describe neither an event nor a state; nor do they enter into any role relationships. Their only contribution is to place the event described by kiss in time and to express modality and aspectuality. They are therefore assumed not to form part of the lexical-thematic structure of a sentence, but are claimed to be part of the functional structure.

13 The assumption that Afrikaans is underlyingly SVO is in line with the proposal by Kayne (1994) that all languages are SVO. Traditionally Afrikaans has been assumed to be an SOV language like, e.g., German and Dutch. The latter assumption was made to account for the fact that in embedded sentences finite lexical verbs appear in the sentence-final position in Afrikaans (and German and Dutch), as in

hy glo dat hy sy vrou soen
he believes that he his wife kisses

On an SVO analysis of Afrikaans D-structure, by contrast, the verb-final surface order is derived by moving the object NP out of VP to a higher functional position in the tree structure.

Note too that the second nie in Afrikaans is not represented in (4). As the status of the second nie in Afrikaans is controversial, it is simply ignored for ease of exposition. See Oosthuizen (1998) for a recent analysis of negatives in Afrikaans.

14 For ease of exposition many of the details of the derivation of the relevant Afrikaans and French sentences have been ignored or glossed over in (4) and (5). Firstly, the inflectional morphemes that spell out the tense and agreement features of verbs are all given under $T$. In fact there is difference of opinion as to whether it is the inflectional morphemes themselves or only abstract features that are generated under the functional nodes. Within the most recent version of generative syntactic theory - the syntactic theory proposed within the Minimalist Program - lexical items enter the derivation fully inflected. The tense, agreement, etc. features associated with the inflectional morphology are then checked against the corresponding features of AGR, $T$, etc.)

Secondly, the internal structure of AGR after movement of the verb to this position is not given in (\$). Moved heads are assumed to adjoin to the positions to which they move. Also, the entire constituent (i.e. [v soen ]) and not just the lexical expression which it contains (i.e. [soen]) is assumed to move and to be replaced by a trace. In (5) only lexical expressions are shown as having moved. 
Thirdly, Afrikaans is a so-called V2 language. This property of Afrikaans has implications for the derivation of main clauses which are not shown in (5), but which will be discussed further on.

15 See Haegeman (1994:601) and the references cited there for some discussion of affix lowering.

16 Lowering of tense and agreement features onto the lexical verb in VP is not possible if there is a not in the sentence, hence the need for insertion of do to host the stranded features. See Schwartz (1993) for discussion.

17 The parametrical difference between languages which gives rise to the phenomenon that some languages do while others do not have the property of being V2 also has to do with the value of a feature of AGR. It has been proposed that in V2 languages $A G R$ has the feature [-accessible] while in non-V2 languages AGR bas the feature [+ accessible]. A discussion of this proposal would entail an excursion into the technicalities of syntactic structure as conceived within the Minimalist Program. The interested reader is referred to the very helpful discussion in Oosthuizen and Waher (1996), or to the original proposal in Zwart (1993).

18 In the case of one of the subjects, François, French is not strictly speaking a second language, but rather a fourth language. Apart from being bilingual in Afrikgans and German, François also knows English. However, for purposes of this paper no distinction is made between a second, third, fourth, etc. language, as noted in the Introduction.

19 Strictly speaking, this sentence is ill-formed. However, it is not impermissible word order that is responsible for the ill-formedness. Rather it is the lack of agreement between the morphological form of the verb and the person and number features of the subject which causes the sentence to be ill-formed: est is $3^{\text {rd }}$ person singular, while les parents is $3^{\text {rd }}$ person plural. As we are interested only in word order, sentences that are ill-formed for reasons that do not have to do with word order will not be starred.

20 As a rule only pronominal subjects are inverted in French interrogatives. Thus, i.(a) is more likely to be found in colloquial French than i.(b):

i. (a) Les Dupont, que mangent- ils pour le diner?

the Duponts what eat they for the dinner

(b) Que mangent les Dupont pour le diner?

what eat the Duponts for the dinner 
With some verbs inversion with a full NP subject is quite acceptable, while with other verbs it is not permitted, e.g.

ii. (a) Combien coutent les pommes?
how much cost the apples
(b) *Pourquoi pleure la fille?
why cries the girl
iii. (a) Ou $\quad$ habite Pierre?
where lives Pierre
(b) *Quand lit Pierre ces livres?
when reads Pjerre these books

A discussion of the reasons why some verbs do and others do not permit inversion falls outside the scope of this paper. The important point is that, in Frencb, lexical verbs are permitted to occur to the left of (pronominal) subjects, albeit subject to certain restrictions, whereas this is ruled out completely in English.

21 The French expression est-ce que ('is it (the case) that') serves more or less the same function in French interrogatives as do in English. Thus, (14)(d) Est-ce que Michelle visite ses copaines d onze heures? corresponds to the English sentence Does Michelle visit her friends at eleven o'clock? Est-ce que is also used when inversion of the verb and the subject is not possible, as is generally the case when the subject is a full NP instead of a pronoun - see note 20 above.

22 When asked to correct sentences which she had judged to be unacceptable, Stephanie moved the adverb to the left of the verb. This indicates that her judgement was based on the relative order of the verb and the adverb and not on some other, irrelevant property of the sentences in question.

23 Note that, lexical choices aside, the sentence is not grammatical in French, because of the position of the indirect object pronoun notre. The grammatical equivalent of (20)(a) is Le garcon nous a donné une table à deux. The mechanisms responsible for the surface position of pronominal objects in French will not concern us. It may be noted in passing, though, that whatever these mechanisms are, Stephanie clearly has not acquired them, as she consistently places object pronouns after the lexical verb:

i. Mes amis a donné mes cadeaux sur mon anniversaire.

my friends have given me presents on my birthday

Target: Mes amis $\underline{m}$ 'a donné des cadeaux sur mon anniversaire. 

ii. et Felicity a donné moi des bijoux and Felicity has given me some jewellery
Target: et Felicity $\underline{m}^{\prime} a$ donné des bijoux

As indicated in note 19 , sentences that are ungrammatical for reasons that do not have to do with word order are not starred.

24 François also produced utterances such as the following in the adverb placement task:

$\begin{array}{llll}\text { i. Les sud-africains regardent Egoli TRES ATTENTTVEMENT. } & \text { TR } \\ \text { the South Africans watch Egoli very attentively }\end{array}$

'South Africans watch Egoli keenly.'

ii. Il faut que on netzoie ses dents SOUVENT.

it must that one clean one's teeth often

'It is necessary that one should clean one's teeth often."

In these utterances the adverb is placed at the end of the sentence. This is also a possible adverb position in French. However, as sentence-final adverbs throw no light on the question of whether or not the lexical verb has moved out of VP, they are ignored for purposes of the discussion in this paper.

25 For some discussion of different theoretical views on the role of age in L2 acquisition and the empirical evidence for these views, see e.g. Long (1990) or Gass and Selinker (1994: ch. 9).

26 An often cited example of transfer of training is the overuse of progressive -ing by L2 learners of English. The phenomenon is explained, it is argued, by the high freguency with which the progressive occurs in the input or with which it is practised in the classroom. See e.g. Lightbown (1986) for some discussion. 


\section{REFERENCES}

Albrecht, J.M. 1998. An analysis of the interlanguage grammar of an L2 French speaker. Unpublished MA paper, Department of General Linguistics, University of Stellenbosch.

Atkinson, M. 1992. Children's syntax: An introduction to principles and parameters theory Oxford: Blackwell.

Bley-Vroman, R. 1990. The logical problem of foreign language learning. Linguistic Analysis 20(1-2): 3-49.

Botha, R.P. 1989. Challenging Chomsky. The Generative Garden Game. Oxford: Blackwell.

Botha, R.P. 1995. The world of language. A Carollinian canvas. Stellenbosch Papers in Linguistics (SPIL) 29.

Clahsen, $H$. and P. Muysken. 1989. The UG paradox in L2 acquisition. Second Language Research 5(1): 1-29.

Cook, V.J. and M. Newson. 1996. Chomsky's Universal Grammar. An introduction. $2^{\text {nd }}$ edition. Oxford: Blackwell

Epstein, S.D., S. Flynn and G. Martohardjono. 1996. Second language acquisition: Theoretical and experimental issues in contemporary research. Behavioral and Brain Sciences 19: 677-758.

Felix, S. 1987. Cognition and language growth. Dordrecht: Foris.

Gass, S.M. and L. Selinker (eds). 1994. Second language acquisition. An introductory course. Hillsdale, NJ etc.: Lawrence Erlbaum Associates.

Haegeman, L. 1994. Introduction to Government and Binding theory. $2^{\text {nd }}$ Edition. Oxford: Blackwell.

Hoekstra, T. and B.D. Schwartz (eds). 1994. Language acquisition studies in generative grammar. Amsterdam/Philadelphia: John Benjamins.

Jackendoff, R. 199.4. Patterns in the mind. Language and human nature. Exeter: Basic Books.

Kayne, R.S. 1994. The antisymmetry of syntax. Cambridge, MA: MIT Press.

Krashen, S. 1985. The input hypothesis: Issues and implications. London and New York: Longman.

Lightbown, P.M. 1986. Classroom language as input to second language acquisition. In Pfaff, C. (ed.) 1986. First and second language acquisition processes. Cambridge, MA: Newbury House, 169-188. 
Long, M.H. 1990. Maturational constraints on language development. Studies in Second Language Acquisition 12: 251-285.

Nel, Z. 1998. An investigation into the presence of functional projections in the L2 grammar of an Afrikaans-speaking L2 learner of French. Unpublished MA paper, Department of General Linguistics, University of Stellenbosch.

Oosthuizen, J. 1998. the final nie in Afrikaans negative sentences. Stellenbosch Papers in Linguistics (SPIL) 31: 61-94.

Oosthuizen, J. and H. Waher. 1996. Minimalisme: Organisasie, afleiding en woordorde. SuidAfrikaanse Tydskrif vir Taalkunde Supplement 29: 35-67.

Pollock, J-Y. 1989. Verb movement, Universal Grammar and the structure of IP. Linguistic Inquiry 20: 365-424.

Radford, A. 1997. Syntactic theory and the structure of English. Cambridge: Cambridge University Press.

Schachter, J. 1990. On the issue of completeness in second language acquisition. Second Language Research 6(2): 93-124.

Schwartz, B.D. 1993. An alternative account of apparent inaccessibility to UG in L2A. Newcastle and Durham Working Papers in Linguistics 1: 240-250.

Schwartz, B.D. 1996. Parameters in non-native language acquisition. In Jordens, P. and J. Lalleman (eds). 1996. Investigating second language acquisition. Berlin and New York: Mouton de Gruyter, 211-235.

Schwartz, B.D. and R.A. Sprouse. 1994. Word order and nominative case in non-native language acquisition: A longitudinal study of (L1 Turkish) German interlanguage. In Hoekstra and Schwartz (eds). 1994: 315-368.

Schwartz, B.D. and R.A. Sprouse. 1996. L2 cognitive states and the Full Transfer/Full Access model. Second Language Research 12(1): 40-72.

Selinker, L. 1972. Interlanguage. International Review of Applied Linguistics 10: 209-231.

Vainikka, A. and M. Young-Scholten. 1994. Direct access to $X^{\prime}$-theory: Evidence from Korean and Turkish adults learning German. In Hoekstra and Schwartz (eds). 1994: 265-316.

Vainikka, A. and M. Young-Scholten. 1996. Gradual development of L2 phrase structure. Second Language Research 12(1): 7-39.

White, L. 1989. Universal Grammar and second language acquisition. Amsterdam/Philadelphia: John Benjamins Publishing Company. 
White, L. 1992. Universal Grammar: Is it just a new name for old problems? In Gass, S.M. and L. Selinker (eds). 1992. Language transfer in language learning. Amsterdam/Philadelphiz: John Benjamins, 217-232.

Zwart, J-W. 1993. Dutch syntax. A Minimalist approach. Groningen Dissertations in Linguistics 10. Groningen Universiteitsdrukkerij. 